\title{
A UTILIZAÇÃO DA FERRAMENTA GOOGLE FORMS COMO INSTRUMENTO DE AVALIAÇÃO DO ENSINO NA ESCOLA SUPERIOR DE GUERRA
}

\author{
THE USE OF THE GOOGLE FORMS TOOL AS AN EVALUATION SCHOOL \\ TEACHING INSTRUMENT AT THE BRASILIAN WAR COLLEGE
}

\author{
Renata Lúcia de Souza Gaúna Monteiro \\ $1^{\circ}$ Ten (QOCON Ped) adjunta do Centro de Planejamento e Avaliação do Ensino (CEPLAE) \\ da Escola Superior de Guerra. \\ http://orcid.org/0000-0001-9511-0728 \\ Dayane Silva Santos \\ 1ำ Ten (RM2 - T) adjunta do Centro de Planejamento e Avaliação do Ensino (CEPLAE) \\ da Escola Superior de Guerra \\ http://orcid.org/0000-0003-3990-5002
}

Data de submissão: 23/10/2019

Data de aprovação: 24/12/2019

\section{RESUMO}

O presente artigo apresenta um relato de experiência em torno do uso da tecnologia como ferramenta facilitadora das atividades relacionadas à documentação da avaliação do ensino na Escola Superior de Guerra, no Rio de Janeiro, na medida em que apresentam mudanças pragmáticas percebidas em intervalo específico de tempo graças ao uso da ferramenta Google Forms para se criar questionários avaliativos online, deixando de lado o uso dos formulários impressos. Esta simples mudança pragmática revelou-se de grande valia, pois conferiu mais celeridade e sustentabilidade ao processo. Diante desse contexto, a experiência aqui apresentada busca não apenas retratar, mas disseminar as vantagens percebidas graças às transformações ocorridas nos processos de avaliação do ensino, adotados na Escola Superior de Guerra, a partir do uso das Tecnologias da Informação e Comunicação.

Palavras-chave: Avaliação do Ensino. TICs. Google Forms.

\section{ABSTRACT}

This article presents an experience report on the use of technology as a facilitating tool for activities related to teaching evaluation at the War College, Rio de Janeiro, as it shows pragmatic changes detected at a specific time interval thanks to the use of the tool. Google Forms to create questionnaires available online, leaving aside the use of printed forms. This simple pragmatic change has proved to be of great value as it gives more speed and sustainability to the process. Given this context, experience here Receive not only portray, but spread as perceived advantages thanks to the transformations that occurred in the teaching evaluation processes, adopted at the War College, from the use of Information and Communication Technologies.

Keywords: Teaching Assessment. TICs. Google Forms. 


\section{INTRODUÇÃO}

"Enquanto o mundo se modifica com rapidez surpreendente em decorrência, principalmente, do acelerado desenvolvimento tecnológico, o ambiente educacional de modo geral mantém os mesmos métodos utilizados há séculos" (MATHIAS; SAKAI, 2013). Este cenário requer mudanças conforme as demandas da sociedade pós-moderna, onde atenta às transformações engendradas pela chamada revolução científico-tecnológica e às necessidades da economia.

Conforme Kenski (2012), ao refletir sobre as questões que envolvem os conceitos de educação e tecnologia, onde afirma que a expressão "tecnologia" "diz respeito a muitas outras coisas além das máquinas. O conceito tecnologia engloba a totalidade de coisas que a engenhosidade do cérebro humano conseguiu criar em todas as épocas, suas formas de uso, suas aplicações".

O conceito de tecnologia compreende tudo o que é construído pelo homem a partir da utilização de diversos recursos naturais, tornando-se um meio pelo qual se realizam atividades com objetivo de criar ferramentas instrumentais e simbólicas, para transpor barreiras impostas pela natureza, estabelecer uma vantagem, diferenciar-se dos demais seres irracionais (KENSKI, 2012, p. 22).

Sendo assim, a linguagem, a escrita, os números e o pensamento podem ser considerados tecnologia. Para Kenski (2012, p. 24), o conjunto de

[...] conhecimentos e princípios científicos que se aplicam ao planejamento, à construção e à utilização de um equipamento em um determinado tipo de atividade, chamamos de "tecnologia". Para construir qualquer equipamento-uma caneta esferográfica ou um computador -, os homens precisam pesquisar, planejar e criar o produto, o serviço, o processo. Ao conjunto de tudo isso, chamamos de tecnologias (KENSKI, 2012, p. 24).

$\mathrm{Na}$ Escola Superior de Guerra (ESG), não está sendo diferente, as tecnologias estão sendo utilizadas para melhorar o desempenho dos processos de trabalho, dentre os quais destacam-se os benefícios diretos na forma como são realizadas as avaliações do ensino.

Tais avaliações têm sido um dos meios mais poderosos para repensar as mudanças estruturais e pedagógicas dos cursos implementados na ESG. Os resultados por ela obtidos refletem os questionamentos em busca da qualidade e eficiência. Assim, avaliar os resultados supõe também a existência de uma metodologia adequada de coleta de informações que seja precisa e objetiva.

É importante observar que a avaliação não pode ser usada como instrumento reducionista, como se avaliar pudesse simplesmente limitar-se à aplicação de meios para a coleta de dados. O conceito de avaliar deve ser um componente do processo educativo, que tem como finalidade orientar todo o processo de ensino.

Frente ao exposto, pensar em desenvolver uma nova postura avaliativa requer desconstruir e reconstruir a concepção e a prática de avaliação. Isto remete a uma reflexão em torno de algumas questões básicas que constituem a compreensão epistemológica e pedagógica do conceber e do fazer avaliativo. Tais questões estão associadas com: Para que avaliar? O que avaliar? Quando avaliar? Como avaliar e o que fazer com os resultados da avaliação? O domínio dessas perguntas contribui para promover mudanças consistentes, sistemáticas e intencionais nas formas de avaliar.

Sendo assim, o instrumento de avaliação tem função estratégica na coleta e variedade de informações sobre um determinado objeto, pois quanto mais informação 
obtiver, maiores serão as condições de compreendê-lo e de adotar as decisões necessárias quanto à trajetória/percurso do fazer avaliativo.

Sabe-se que as tecnologias têm impactado a educação de tal maneira que têm mudado a sua forma de concepção, demandando o repensar de metodologias, estratégias e, inclusive, o modo de se comunicar.

Nesse sentido, este relato de experiência tem por objetivo disseminar as transformações ocorridas nos processos de avaliação do ensino adotados na Escola Superior de Guerra, a partir do uso das Tecnologias da Informação e Comunicação (TICs). Para alcançar tal objetivo, este trabalho busca apresentar como ocorre o processo de avaliação do ensino adotado nos cursos da ESG, entender as mudanças ocorridas nesse processo frente às tecnologias e, por fim, identificar as contribuições que as ferramentas Google Forms trouxeram nas formas de avaliar.

A escolha do tema ocorreu a partir de reflexões sobre a importância da realização do processo avaliativo com uso das TICs, tendo em vista as facilidades promovidas pelo uso das ferramentas tecnológicas; e sobre o real sentido e aplicabilidade do conceito de avaliação, quando se pensa em realizar ações que busquem a melhoria e/ou aperfeiçoamento de um dado objeto.

Para tanto, tomou-se como base o trabalho pedagógico desenvolvido pelo Centro de Planejamento e Avaliação do Ensino (CEPLAE), da Escola Superior de Guerra. Para o embasamento teórico, foram adotados os conceitos de avaliação de Luckesi (2011) e Luck (2014) e os conceitos envolvendo as TICs de Castells (2011), Green e Bigun (1995), Kenski (2012) e Silva e Spanhol (2014).

$\mathrm{Na}$ primeira parte do artigo, são apresentados os referenciais teóricos utilizados para embasar o trabalho. Já na segunda parte deste estudo, buscou-se dissertar acerca dos procedimentos metodológicos. Na sequência, relatou-se a experiência do uso do Google Forms nos processos de avaliação adotados nos cursos da Escola Superior de Guerra (apresentação e análise de dados). E, por fim, foram apresentadas as conclusões a respeito dos resultados obtidos a partir do uso da ferramenta Google Forms.

\section{REFERENCIAL TEÓRICO}

Entende-se por avaliação o conceito amplamente difundido por Luckesi (2011), que afirma que o processo de avaliar implica um ato de atribuir valor ou juízo de qualidade sobre um dado objeto. Tal conduta requer um posicionamento, quer seja positivo, quer seja negativo sobre o que está sendo avaliado. Com isso, percebe-se que o processo de avaliar transcende o simples ato de verificar.

Ainda segundo o Luckesi (2011), enquanto o ato da verificação se relaciona somente com o processo de obtenção das informações que se buscam, encerrando-se no momento em que o objeto chega a ser configurado; o ato de avaliar ultrapassa a simples obtenção da configuração do objeto, exigindo uma decisão do que fazer com ele.

Luckesi (2011, p. 52) afirma que, "o ato de avaliar não se encerra na configuração do valor ou qualidade atribuída ao objeto em questão, exigindo uma tomada de posição favorável ou desfavorável ao objeto de avaliação, com uma consequente decisão da ação". 
O autor complementa tal assertiva ao reforçar que o processo de avaliação "direciona o objeto numa trilha dinâmica de ação" (LUCKESI, 2011). Isto porque o ato de avaliar envolve:

A coleta, análise e síntese dos dados que configuram o objeto da avaliação, acrescido de uma atribuição de valor ou qualidade, que se processa a partir da comparação da configuração do objeto avaliado como um determinado padrão de qualidade previamente estabelecido para aquele tipo de objeto. O valor ou qualidade atribuídos ao objeto conduzem a uma tomada de posição a seu favor ou contra ele. E o posicionamento a favor ou contra o objeto, ato ou curso de ação, a partir do valor ou qualidade atribuídos, conduz a uma decisão nova: manter o objeto como está ou atuar sobre ele (LUCKESI, 2011, p. 52).

No entanto, a avaliação "é um processo complexo que necessita de objetivos claros, estratégias para obter evidências de resultados e interpretações que possam apresentar a formulação de juízo de valor visando à tomada de decisão" (LUCKESI, 2003).

Luck (2014) explicita que a avaliação é função inerente de toda prática educacional, se tornando necessária para verificar em que medida as ações produzem resultados a que se propõem. Ainda segundo a autora, o processo avaliativo "possibilita a realimentação (feedback) do planejamento e de suas respectivas ações, a partir de observações, análises, reflexões e julgamentos que possibilitam identificar aspectos que necessitam de reforço, revisão e redirecionamento" (LUCK, 2014, p. 25).

Pensar sobre o assunto em lide nos traz a consciência sobre a importância dos processos avaliativos na prática educativa. Contudo, é preciso compreender que o mundo do século XXI encontra-se em constantes mutações, que impactam as relações que 0 homem estabelece com a sociedade.

Castells (2011) aborda tal fato quando diz que os avanços tecnológicos romperam com as relações estabelecidas entre homem e sociedade. $\mathrm{E}$ de fato as crescentes inserções da tecnologia em todos os setores da sociedade trouxeram uma disseminação de informação em ampla escala e em maior velocidade devido à globalização, abrindo espaço para o ser humano buscar novos conhecimentos através de novos meios de comunicação. Para o autor, esse fenômeno trouxe transformações que representam a própria base desse novo paradigma.

A primeira característica de acordo com Castells (2011) é ter a tecnologia agindo sobre a informação disseminando conhecimento, dando origem à sociedade informacional.

A segunda característica diz respeito à entrada e aos efeitos das novas tecnologias na sociedade, moldando tanto os processos individuais, quanto coletivos do ser humano.

Já a terceira característica está centrada na lógica de redes, cujo princípio parte da utilização das TICs para operacionar um conjunto de relações. E, atrelada a essa, está a quarta característica, que representa a convergência das TICs na formação de um sistema totalmente integrado.

E, por fim, a quinta e última característica, baseada na ideia da flexibilidade, sobre a qual está interligada a intensa capacidade de reconfiguração dessa nova sociedade, marcada por constante mudança organizacional.

Esses aspectos do novo paradigma influíram na transformação da sociedade que passou a se tornar digital. Em virtude dessa conjuntura de fatores, passou a se conceber uma nova visão de mundo. Seria um "novo mundo" conduzido pelas inovações tecnológicas. 
Para Green e Bigun (1995), a influência tecnológica que sofremos diariamente marca todo esse novo contexto social chamado de "ecologia digital", cuja distribuição de informações se dá instantaneamente, superando a velha realidade espaço-tempo, distorcendo a ordem ilusória da percepção normal.

Kenski (2012, p. 22) corrobora a assertiva acima ao reiterar que "na atualidade o surgimento de um novo tipo de sociedade tecnológica é determinado principalmente pelos avanços das tecnologias digitais de comunicação e informação e pela microeletrônica".

Assim como em todo contexto sócio-histórico-cultural, as TICs têm impactado na educação de tal maneira que têm mudado a sua forma de concepção, demandando o repensar de metodologias e estratégias arcaicas.

Essas novas tecnologias abrangem uma variedade muito grande de ferramentas, dentre as quais se destaca o Google Forms, que é o objeto deste estudo. Diante desses avanços, tais tecnologias assumem a função de suporte do processo educativo.

Silva e Spanhol (2014, p. 34) afirmam que "as mídias amparadas pelas tecnologias precisam ser trabalhadas como elementos indissociáveis de ambiente educacional qualificado, pois são inseparáveis para [...] aprender e trabalhar em uma sociedade do conhecimento". Os autores, ao discorrerem sobre o papel das TICs no ambiente educativo, explicitam que as mídias correspondem a um conjunto de ferramentas tecnológicas de suporte à informação, enquanto a tecnologia se caracteriza como "o artefato para comunicar as mensagens que, uma vez preparadas, serão apresentadas em mídias" (SILVA; SPANHOL, 2014, p. 37).

Observa-se que os recursos tecnológicos permitem ao usuário uma maior interatividade a partir da relação que ele estabelece com a máquina, em busca de informações.

Com isso, percebe-se que não há como se pensar no processo educativo sem levar em consideração a importância das TICs. Kenski (2012), ao tratar a relação entre tecnologias, técnicas e equipamentos, apresenta a seguinte reflexão:

Pense como seria a sua vida - e a de qualquer pessoa - se não tivéssemos as tecnologias nos ajudando a realizar as nossas atividades diárias. Eu não poderia agora, por exemplo, estar me comunicando com você, contando essa longa história de relacionamentos bem-sucedidos entre os homens e as tecnologias (KENSKI, 2012, p. 25).

É importante reconhecer que a tecnologia, entre suas infinitas possibilidades, contribui também para a qualidade da educação, no momento em que dinamiza e otimiza atividades que antes demandavam muito tempo no ambiente escolar. Deve-se entender que a utilização das TICs na educação pode transcender a visão limitada de um objetivo instrumental, possibilitando assim sua utilização em determinado contexto e situações do processo de ensino e aprendizagem.

Assim, as tecnologias vêm sendo utilizadas em diversas maneiras e em vários ramos de atividades, podendo se destacar na produção, armazenamento e disseminação de informação onde poderão ser utilizadas para elaborar, experimentar e avaliar produtos educacionais de acordo com o contexto em que estão inseridas. 


\section{METODOLOGIA}

O trabalho aqui apresentado relata a experiência de anos de observação (fevereiro de 2011 até dezembro de 2018), em torno do processo de avaliação do ensino adotado pelo Centro de Planejamento e Avaliação do Ensino (CEPLAE) com o uso da ferramenta Google Forms, no Curso de Altos Estudos em Políticas e Estratégias (CAEPE), na Escola Superior de Guerra.

Dentre suas funções, o referido setor realiza a coordenação dos processos avaliativos empregados na ESG. Nele atua a equipe pedagógica composta, dentre tantos, por pedagogos, cuja responsabilidade está na coleta das opiniões dos estagiários sobre as atividades de estudos planejadas para o CAEPE. Isso envolve as etapas de preparação, de manutenção, de coleta e de análise dos dados.

Para o cumprimento de tal missão, desde o ano de 2011, o CEPLAE procura traçar um caminho para subsidiar os processos de avaliação do ensino adotados na Escola Superior de Guerra, para, como produto final, ter maior facilidade em coletar a devolutiva dos cursos relacionados ao parecer dos estagiários.

Isto porque os dados coletados em torno das opiniões dos estagiários são analisados e transformados em relatórios. Ressalta-se, com isso, que o relatório final é remetido para a apreciação do Comando e Subcomandante da ESG, para que, em reunião, os envolvidos nos cursos possam pensar em estratégias de replanejamento.

Quando os processos de avaliação começaram a ser implementados, utilizavamse formulários impressos, nos quais os estagiários expressavam suas opiniões de maneira manual. Isto gerava algumas consequências que serão descritas abaixo.

A primeira consequência está relacionada com a morosidade na coleta dos dados, isto porque como o curso apresenta um elevado quantitativo de estagiários, a Equipe Pedagógica perdia muito tempo no momento da tabulação e compilação dos dados, haja vista que essa etapa do processo pedagógico demandava algumas semanas para sua conclusão.

Outra consequência bastante recorrente refere-se às dificuldades encontradas pela Equipe Pedagógica de compreender a escrita contida nas respectivas fichas de avaliação do ensino, no momento da compilação dos dados expressos. Como os formulários eram impressos e os estagiários o preenchiam de forma manual, era comum encontrar algumas grafias difíceis de serem compreendidas, gerando muita dificuldade e confusão para interpretar o que estava escrito.

Além dos pontos elencados acima, também havia muito acúmulo de papel e gastos excessivos pelo uso desse material, o que impactava diretamente nas questões de cunho socioambiental, posto que o volume de formulários impressos demandava recursos de caráter financeiro e humano, no momento da compra e preparação das referidas fichas.

O uso do questionário online trouxe uma melhora significativa no que diz respeito à preparação, à manutenção e à coleta dos dados das fichas de avaliação. Há de se destacar as vantagens abaixo relatadas.

Os questionários online, adotados a partir de fevereiro do ano de 2011, tornaram os processos avaliativos dinâmicos e céleres, porque permitiu que os estagiários emitissem suas opiniões em tempo real. Dessa forma, a Equipe Pedagógica pôde extrair os dados 
das referidas fichas, não necessitando destinar um tempo maior para a coleta e tabulação dos dados.

Dentre os benefícios para a Equipe Pedagógica, destaca-se a possibilidade de dar maior ênfase para a etapa fundamental do fazer pedagógico: analisar os dados extraídos das fichas para elaboração dos relatórios pedagógicos, que são imprescindíveis para a tomada de decisão e aperfeiçoamento dos cursos realizados na ESG.

Deixou de existir a dificuldade relacionada com a questão da grafia, tendo em vista que o preenchimento online adota uma fonte impressa padrão, no qual facilita a leitura e, consequentemente, a compreensão das opiniões expressas.

Outra vantagem bastante significativa quanto ao uso dos questionários online diz respeito à economicidade dos recursos financeiros, tendo em vista que não se torna necessária a impressão das fichas de avaliação, posto que elas podem ser respondidas com o uso do computador e smartphones, bastando ter acesso à internet.

Observa-se também que há o cuidado com as questões socioambientais, haja vista que, como a plataforma do Google armazena os questionários avaliativos, não há necessidade de realizar impressões dos questionários, tampouco de armazená-los.

Devido às inovações tecnológicas e às novas formas de informação e comunicação, houve a implementação das ferramentas do Google Drive para coletar as apreciações dos estagiários.

A realização das avaliações pelo Google Forms representa um avanço na condução das atividades avaliativas adotadas na Escola Superior de Guerra, pois servem de subsídios para pensar no replanejamento das atividades de estudo do curso e realizar a tomada de decisão com relação aos pontos que necessitam ser revistos em virtude do mau desempenho.

É nesse contexto que a tecnologia auxiliou a implementação de uma avaliação mais sustentável e célere na Escola Superior de Guerra. Entretanto, variados métodos vão surgindo com a evolução do conhecimento tecnológico e podem ser modelados para serem utilizados em diferentes realidades educacionais.

Kalinke e Santos (2014) afirmam que as variadas atividades realizadas em diferentes ambientes e soluções tecnológicas podem ser usadas no processo de ensino como o Facebook, Orkut, Google+, Skype, Twitter, Youtube e outros recursos como fóruns de discussão, e-mail, jogos, revistas, tv, rádio online e downloads.

\section{ANÁLISE E DISCUSSÃO E RESULTADOS}

O Google Drive é um serviço que possibilita de forma gratuita uma série de aplicativos que permitem a edição colaborativa, disponibilização, backup e portabilidade de arquivos.

Dentre suas vantagens, está a possibilidade de armazenar no servidor do Google os arquivos criados, possibilitando ao usuário poder acessá-los a partir de qualquer computador conectado à internet. Outra vantagem diz respeito à realização do upload de 
arquivos do computador do usuário, tornando-os igualmente acessíveis a outras máquinas que também estejam conectadas.

Para Heidemann e Oliveira (2010), o Google Drive é considerado uma "evolução natural" do Google Docs. Tal plataforma congrega o Google Forms e mais um leque de aplicativos de produtividade, que oferecem a edição de documentos, folhas de cálculo, apresentações e muito mais. Dentre esses aplicativos, encontram-se o Google Documents, o Google Spreadsheets, o Google Presentations e o Google Drawings.

A ferramenta do Google Forms possibilita personalizar os questionários com cores, criar diversos tipos de perguntas, como de múltipla escolha, caixas de checagem, escalas, listas suspensas, etc., usar vídeos e imagens para ilustrar e deixar as perguntas que estão sendo feitas mais claras, fazer uso de diversos templates prontos do Google Forms, acessar os questionários do Google Forms em smartphones e tablets, seja para responder ou criar seus questionários. Em suas funcionalidades, destacam-se o tempo no processo de coleta e análise de dados e a manipulação de enormes pilhas de documentos. Os questionários online emitidos por esse serviço permitem a coleta organizada das respostas, poupando tempo e dando melhores condições para se fazer as análises comparativas.

Para a ESG, a ferramenta do Google Forms possibilita a criação das fichas de avaliação adotadas pelos estagiários dos cursos para a emissão de julgamento de valores sobre as atividades de estudos adotadas. São consideradas como atividade de estudos as palestras/conferências ministradas, as viagens e as visitas de estudos.

Atualmente, os relatórios gerados servem para possíveis intervenções no sentido de aprimorar o processo de avaliação do ensino, pois as respostas apresentadas pelos estagiários são geradas em forma de gráficos e textos, contendo os percentuais e apontamentos individuais dos estagiários. Com esses dados, as informações são tratadas e transformadas em relatório para que possam subsidiar as mudanças necessárias para 0 curso.

\subsection{Apresentação e análise dos dados coletados}

O instrumento utilizado no processo avaliativo da ESG, cujos dados do mês de abril de 2018, encontra-se aqui narrado de fato, um modelo de questionário online do Google Forms com perguntas fechadas e abertas.

Nas perguntas do tipo fechada, as opções de resposta são em formato de múltipla escolha adotando-se critérios como sim, não, em parte e não participei da atividade.

Nas perguntas do tipo aberta, é dado liberdade para o estagiário escrever seus apontamentos sem restrição de palavras.

Com o questionário online criado, é feita uma reunião no setor pedagógico para avaliar se as questões propostas estão de acordo com o que se busca analisar nos processos educativos implementados no referido curso.

Após a revisão do questionário, os estagiários recebem o endereço eletrônico (link) da ficha de avaliação do ensino em seus e-mails pessoais para realizar o acesso a elas. Ao clicar no link, os estagiários são remetidos diretamente para a ficha de avaliação de ensino alocada no Google Forms, para expor suas apreciações sobre as atividades de estudo.

Os estagiários analisam nesta ficha de avaliação aspectos como pertinência do conteúdo, adequação do tempo, garantia do debate, aplicabilidade dos conhecimentos, contribuição das palestras para o alcance dos objetivos do curso, adequação da carga 
horária, nível de profundidade dos conteúdos, estruturação dos conteúdos, a didática do palestrante no que se refere aos domínios e atualização dos conteúdos, oralidade e os recursos instrucionais utilizados pelos palestrantes.

Para melhor demonstrar a utilidade do questionário online, na Figura 1 a seguir, é possível exemplificar a "questão do conteúdo" que foi tratado na unidade de estudo por meio da seguinte pergunta: O conteúdo abordado foi pertinente?

Figura 1 - ESG - Imagem do Questionário

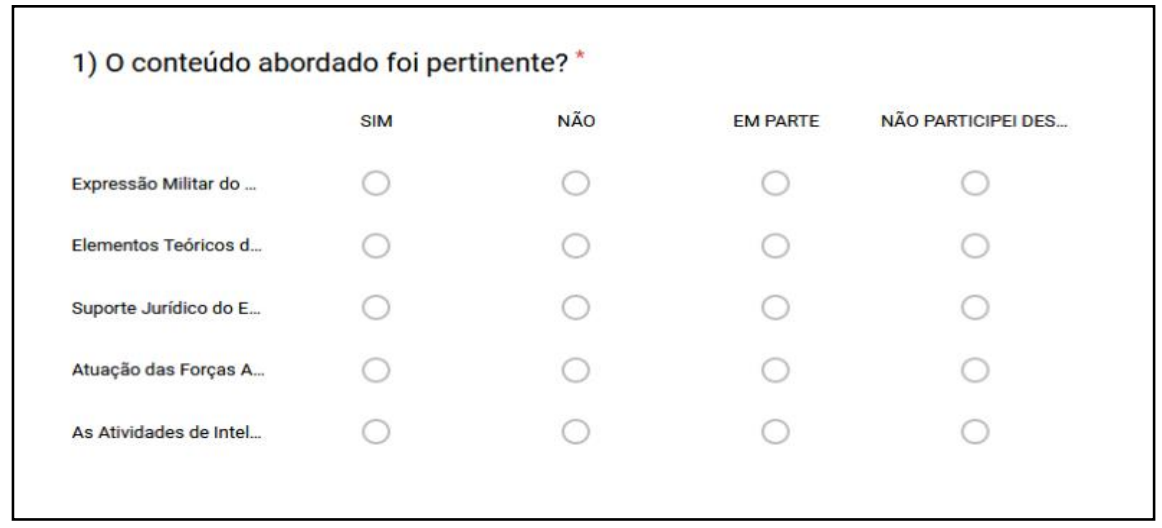

Fonte: CAEPE, 2018.

Com base na Figura 1, é possível exemplificar uma das perguntas do tipo fechada que o questionário apresenta. Nesse tipo de pergunta, verifica-se que são apresentadas algumas opções de escolha para que o estagiário avalie uma determinada temática. Isso torna o questionário mais célere, visto que em apenas um clique ele consegue preencher sua opção de escolha.

Isto traz um benefício para o estagiário, pois o preenchimento, que outrora era enfadonho e moroso por ser feito em papel, passa a ser, com o questionário online, ágil, deixando de ser cansativo preenchê-lo.

As respostas podem ser dadas de acordo com a escolha do respondente (múltipla escolha); após essa fase, os resultados obtidos após o preenchimento são facilmente exportados para planilhas eletrônicas, que emitem automaticamente os valores totais de respondentes, separando os percentuais de acordo com os critérios estabelecidos nas fichas de avaliação.

O Google Forms realiza a sistematização dos resultados das apreciações dos estagiários e emite os resultados formatados em dados quantitativos, sob a forma de gráfico e dados qualitativos, sob a forma de respostas dissertativas, facilitando a compilação de tais dados e a construção dos relatórios pedagógicos.

Desse modo, na Figura 2, é possível verificar como o Google Forms emite os resultados quantitativos das respostas fornecidas pelos estagiários. De acordo com o número de respostas, são gerados gráficos com o número de respostas baseadas nos quesitos estipulados nas perguntas, à medida que os estagiários vão respondendo. 
Figura 2 - ESG - Imagem do Questionário

1) 0 conteúdo abordado foi pertinente?

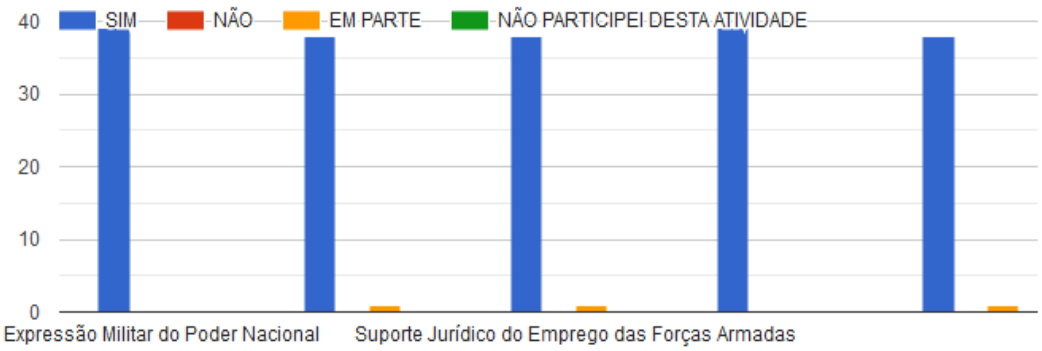

Fonte: CAEPE, 2018.

Na Figura 2, pode-se evidenciar a forma como os dados quantitativos são tabulados pelo Google Forms. Isto demonstra outra vantagem do uso da ferramenta do Google, pois com a emissão automática dos percentuais passou-se a não ter a necessidade de a Equipe Pedagógica realizar manualmente os cálculos para encontrá-los.

Antes do uso do Google Forms, perdia-se muito tempo realizando cálculos matemáticos para encontrar os resultados das apreciações dos estagiários. Isto atrasava bastante a emissão dos relatórios pedagógicos. Contudo, a tabulação dos dados matemáticos realizados pelo Google Forms se tornou benéfica, pois fez com que a emissão dos relatórios pedagógicos se tornasse mais rápida, haja vista que a ferramenta emite automaticamente os percentuais necessários para realizar as análises pedagógicas.

É possível também extrair dados qualitativos das respostas fornecidas pelos estagiários através do Google Forms. A qualquer momento pode ser observado como está o andamento da pesquisa, ou seja, a análise pode ser realizada em tempo real, como se observa na Figura 3.

Figura 3: ESG - Imagem do Questionário

Caso a adequação do tempo não tenha sido suficiente, comente:

3 respostas

Os tempos são suficientes. No entanto, se o docente abrir para intervenções antes do período do debate, tem que correr com a palestra no final. Isso ocorreu com todos.

\footnotetext{
Expressão Economica do Poder Nacional é uma disciplina complexa e atrativa que merece maior tempo de dedicação.

As demais disciplinas o tempo foi suficiente para o que foi explanado, ou seja, limitou-se a exposição de transparencias com dados não atualizados.

Os temas são extremamente relevantes, poderia ter uma carga horária maior, foi muito bom, mas poderia ser melhor
}

Fonte: CAEPE, 2018.

Com as respostas qualitativas, é possível entender de maneira mais ampla as percepções dos estagiários no que se refere aos aspectos perguntados, e na análise dos dados, essas colocações realizadas tornam o relatório mais consistente.

Percebe-se também que a plataforma facilita o trabalho de tabulação dos dados, a partir do momento em que a própria ferramenta emite um extrato das respostas em forma de gráficos e textos. 
Além disso, há um menor desgaste humano nas etapas de execução do processo; menor preocupação no tempo com a compilação e tratamento dos dados; além de possíveis imprevistos que poderiam surgir nos procedimentos de preparação das fichas: digitar o questionário, realizar a impressão ou o processo de cópias, irem ao local da aplicação, aplicar o questionário informando as devidas orientações, aguardar as respostas de todos os estagiários.

Ressalta-se que antes do uso de tal ferramenta, a tabulação dos dados demandava muito tempo, pois o serviço era realizado de forma manual, haja vista a necessidade de realização de cálculos para obtenção dos dados matemáticos.

Com o uso do Google Forms percebeu-se que os dados passaram a ser emitidos de forma rápida, contribuindo para a celeridade na constituição dos relatórios pedagógicos que servem de subsídios para realização do julgamento de valor, tomada de decisão e, consequentemente, o replanejamento do curso.

\section{CONSIDERAÇOES FINAIS}

O uso do Google Forms para conferir mais celeridade e sustentabilidade ao processo avaliativo documental da Escola Superior de Guerra foi bastante positivo, principalmente no que diz respeito à economia, pois a transição para o uso dos questionários online produziu uma série de transformações benéficas para o processo de avaliação, dentre as quais se destaca a economia coletiva relacionada, por exemplo, com os recursos financeiros destinados para tornar viável a realização da avaliação em meio físico.

Observou-se que a facilidade das tecnologias na coleta das informações e no acesso aos questionários otimizaram o tempo demandado pelos estagiários para 0 preenchimento das fichas e tornou mais célere a forma de tratar os dados.

Percebe-se, com isso, que não houve apenas uma mudança na ferramenta, mas sim de toda a atividade de gerenciamento dos questionários, pois o Google Forms traz consigo uma bagagem de recursos que facilitam a adoção de estratégias mais rápidas para a execução do trabalho da equipe pedagógica.

Atualmente, os relatórios gerados servem para possíveis intervenções no sentido de aprimorar o processo de avaliação do ensino dos cursos, pois as respostas apresentadas pelos estagiários são geradas em forma de gráficos e textos, contendo os percentuais e apontamentos individuais dos estagiários. Com esses dados, as informações são tratadas e transformadas em relatório para que possam subsidiar as mudanças necessárias para o curso.

A utilização do sistema do Google produz resultados relevantes, pois podem ser acessados em computadores nos laboratórios de informática, biblioteca, nas residências, e também por smartphones. O estudo demonstra que o sistema foi útil, prático e de simples manuseio atendendo a todas as expectativas no que se refere ao trato das avaliações do ensino da ESG. 


\section{REFERÊNCIAS}

CASTELLS, M. A sociedade em rede - a era da informação: economia, sociedade e cultura. 6. ed. São Paulo: Paz e Terra, 2011.

GREEN, B.; BIGUM, C. Alienígenas em sala de aula. Tradução e organização: Tomaz Tadeu da Silva. Petrópolis, RJ: Vozes, 1995.

HEIDEMANN, L. A.; OLIVEIRA, A. M. M. Ferramentas online no ensino de ciências: uma proposta com o Google Docs. Física na Escola, v. 111, n. 2, 2010.

KALINKE, M. A.; SANTOS, L. M. O uso de multiambientes em trabalhos colaborativos. Revista Tecnologias na Educação, ano 6, n. 11, dez. 2014.

KENSKI, V. M. Educação e tecnologias: um novo ritmo da informação. 8. ed. Campinas: Papirus, 2012.

LUCK, H. Planejamento em orientação educacional. 23 ed. Petrópolis, RJ: Vozes, 2014.

LUCKESI, C.C. Avaliação da aprendizagem: estudos e proposições. 22 ed. São Paulo: Cortez, 2011.

LUCKESI, C. C. Avaliação da aprendizagem escolar. São Paulo, Cortez, 2003.

MATHIAS, S. L.; SAKAI, C. Utilização da Ferramenta Google Forms no Processo de Avaliação Institucional: Estudo de Caso nas Faculdades Magsul. 2013. Faculdades Magsul (FAMAG). Eixo I - Criação de estratégias e metodologias para o trabalho das CPA. Disponível em:

<http://download.inep.gov.br/educacao superior/avaliacao institucional/seminarios region ais/trabalhos regiao/2013/centro oeste/eixo 1/google forms processo avaliacao instit estudo caso faculdades mag.pdf>. Acesso em: 01 nov. 2019.

SANTOS, D.S.D. Um olhar sobre o curso plano de ação em emergência em postos de serviços da Petrobras Distribuidora. Rio de Janeiro: UFRJ, 2012. 51p.

SILVA, A. R. L da; SPANHOL, F. J. Design instrucional e construção do conhecimento na ead. Jundiaí: Paco Editorial: 2014. 